MEMORABILIA IN THE

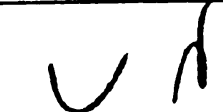

\section{HISTORY OF THE BRITISH MEDICAL ASSOCIATION.}

Boing part of an Adtriss delivered at the Annual Mictins of the Kiading Branch.

BY GEORGE MAY, JUN., EsQ.,

President of the Branch; Surgeon to the Royal Berkshire Hospital; etc.

ThE question has often been put to me, Why should I join the Asso. ciation? What good has it ever done? I propose to devote the time at our disposal to a brief review of what the Association has done for the public and for the profession.

The Provincial Medical and Surgical Association was founded by Dr. Hastings at a meeting of fifty medical men in the Board Room of the Infirmary at Worcester in July 1832 . It consisted of 150 members increased before the end of the year to 310. It was not formed in imitation of the British Association for the Advancement of Science, which had been established the previous year, but arose from the success of the Midland Medical and Surgical Reporter. Its objects were-

1. Social. - To promote friendly intercourse at the annual meetings.

2. Ethical. - To check the spirit of misrule and confusion which actuated the profession, by the influence of public opinion, and by establishing harmony and good feeling.

3. Scientific. - To develope the science of medicine by collecting the results of individual experience.

The managing body consisted of a President and a Council, to repre. sent districts, to collect subscriptions, and to decide on the essays to be published.

Before attempting to trace the results due to the Association, it may be useful to regard for a moment the condition of the medical profession at the time of which we speak. Medicine may be regarded as a science, an art, or a trade. The time was long past when Dr. Sangrado could treat his patients with copious draughts of warm water, and call in the barber-surgeon to finish his work by free venesection; or when Gil Blas could give his client the exclusive right to poison his Majesty's subjects by the sale of drugs ; or when, in our own country, Dr. Reid was allowed to erect a stage for the sale of drugs, the surgeon in addition being allowed to use music, but both being wisely ordered not to hinder people from coming to the pump. But at this time medicine was something between a trade and an art. Regarded as a mere trade, the practice of physic required but little skill, the qualities best suited for insuring a prosperous career having no necessary connexion with intellect or science. An imposing manner, confident pretension, verbose declamation interlarded with high sounding terms, however unintelligible or unmeaning, unhesitating assurance of cure, condemnation of whatever antecedent practitioners had done-these and various still less worthy arts will suffice to gain a reputation sufficient to satisfy the cupidity of whoever can desceud so low as to resort to them. Swift laments-

\section{"Deprived of kind Arbuthnot's aid,
Who knew his art, but not his trade."}

I have recently become possessed of a medical account of this period, in which one shilling is charged for barley and gum, and have seen another sent by a gentleman, once known to most of you, in which sixpence was charged for an oily mixture.

From this condition the profession was just emerging when the Association was founded; and it is curious to notice how completely its founders overlooked the great influence it was destined to exert on what may be called the political aspects of medicine. The first trace of any such action occurred in 1833 , when a letter was sent by the Association to Parliament thanking Government for the determination to record the causes of dcath. In 1835, the Eastern Counties Association was formed, " s to watch over the interests of the profession", and from this time we shall be able to trace the efforts of two distinct and often opposing parties in the Association. But for our present purpose it will be more convenient to take an historical view, only tracing any one subject to its conclusion, where it can easily be so dealt with.

1833. Bristol. - The annual meeting was noted for its recommendation that joint reports should be made on subjects of medical interest. Hitherto this has not attracted the attention it deserves, chiefly from want of financial support ; but it has probably a great future before it. Correspondents were clected to report on the medicine of foreign countries-a field yet unworked by this Association. The offer of a prize for an essay called forth several valuable contributions. Medical reform was foreshadowed in the following truthful description of the President. "By a forced and unnatural division of offices, the profession has been split into departments. Each department has had assigned to it a sepa. rate superintendence, the aim of which has been to advance its interests without reference to the other branches. Government of the profession by separate and independent corporations has been fully tried and utterly failed. We may patiently wait those salutary reforms in medical polity which, sooner or later, an enlightened legislature must accord."

1834. Birmingham.-Members residing in large towns were advised to meet for mutual improvement. This was the first indication of the formation of branches, which have since contributed so largely to the success of the Association.

Provident dispensaries were recommended. This subject has recently received special attention; but, although many flourishing dispensaries are scattered through the country, it has not yet been carried out on the scale which its importance deserves.

1835. Oxford. - The Medical Benevolent Fund was founded.

1840. An elaborate report on vaccination by Mr. Ceely, costing the Association no less than $£ 700$ for illustrations, and which is still recognised as the standard authority on the subject, was followed by the prohibition of inoculation, and led to legislation which is even yet only partially successful in checking the ravages of small-pox. The Physician to the Emperor of Russia joined the Association, and influenced the Russian Government to register the causes of death in that empire.

1842. Life assurance offices were prevailed on to pay the fees of the medical referees.

1848. The retrospective addresses delived at each annual meeting led to the publication of Braithwaite's Retrospect and Ranking's Abstract.

1849. A petition to Parliament to check the Sale of Poisons was speedily followed by Lord Carlisle's Bill to regulate the sale of Arsenic.

1864. Failure of Medical Provident Fund.

1866. This year will ever be memorable in the annals of the Association by the death of Sir C. Hastings, its founder, who for five-andthirty years had devoted himself to promote the best interests of the profession.

Poor-Luw Midical Relief.-Among the subjects which have prominently engaged the attention of the Association, Poor-law reform deserves special mention. So early as 1836 , it was recommended that the parish should pay for drugs. This advice has been followed in many unions to the extent of furnishing cod-liver oil and quinine, and, in large towns, will perhaps shortly lead to the formation of dispensaries, where the poor will obtain the medicines prescribed by the parochial medical officers.

1839. In this year, in consequence of the remonstrances of the Association, the system of tendering for medical Poor-law appointments was abandoned. This practice had led to such results, that we find it officially stated that two hundred and thirty-three Poor-law medical officers were practising without legal qualification.

1870. In this year, the superannuation allowance was extended to Poor-law officers. It must be confessed that the efforts of the Association directly to improve the status of the Poor-law medical officers have hitherto been attended with very partial success; not froin any want of zeal, but because the power which competing corporations possessed to facilitate the admission into the profession of imperfectly educated practitioners has enabled the guardians of the poor to dictate their own terms.

Medical Riform. 1837. Chellenham.-Perhaps in no way has the Association done more for the public good than by its efforts to promote medical reform. In 1837, a Committee was appointed to watch the interests of the profession; and it was recorded that the power of granting qualifications was rested in no fewer than seventeen competing corpora. tions, underselling each other like a Dutch auction. The Committee noticed the imperfections and unequal character of existing methods of qualification for medical licences, and the insufficiency and exclusiveness of medical corporations, with want of power to afford protection to the public and the profession against the arts of ignorant pretenders. It urged the importance of the one portal system, and advised that the profession should be represented; that the uniformity of primary qualification should be tested by sufficient examination; that there should be an equal right to practise throughout Her Majesty's dominions. These remonstrances for the time availed little. In $18+2$, we find that the College of Physicians denied the right of the Association to interfere. The College of Surgeons considered themselves immaculate; and Mr. Guthrie did not see anything to amend.

1846. In this year, registration of practitioners was recommended-a course afterwards carried out by the General Council with marked advantage. 
1852. The Royal College of Surgeons was compelled to accept a charter giving Fellows the right to vote -2 measure to which the im. portant improvements lately adopted by that body can be distinctly traced.

1858. I need not weary you with the details of the struggle which ensued, and which, after having been carried on several years, ended in the passing of Mr. Cowper's Act granting :- I. Registration of qualified practitioners, with cxclusive right to hold medical appointments and to recover remuneration; 2. Reciprocity of practice; 3 . A national Pharmacopaia ; 4. Establishment of a Council with power to exclude from the Register for infamous conduct-a clause which promised to be of very great value. The chief defects of the Act were that it made no adequate provision for uniformity of professional education, and that it failed to give the general practitioner any voice in the selection of the Council. "This last provision is well known to have been long regarded by the Association as of great importance ; and its omission recently caused the rejection of an otherwise very valuable measure of medical reform. A recommendation made several years since may prove a good compromise ; namely, that the General Council should remain unchanged, but that the Councils of each corporation should be elected by the members of each corporation, the right of voting not being restricted to a select few.

Ouackery. - $\mathrm{At}$ the foundation of the Association, there was a spirit of disunion with no recognised standard of authority ; and probably in no way has the Association been of so much service as in its indirect effect on the profession. Medical associations must tend insensibly to form a standard of conduct and feeling to which the majority will by inclination happily conform, the few from motives of self-interest.

Our late friend and colleague, Dr. Cowan, was especially noted for his denunciations of all forms of quackery. At Liverpool, in 1839, he had the holdness to attack, and, in spite of the opposition of vested interests, the good fortune to destroy, an institution supported at Liverpool by many of the chief practitioners of that town, and which possessed a stock of no less than $£ \mathbf{r}, 500$ worth of patent, and therefore secret, nostrums, there being at that time no fewer than six hundred stamped patent medicines; whilst advertisements were daily issued by those holding diplomas, vying with each other in their gross disregard of truth and decency.

In 1849 , the President of the Taunton branch was expelled from the Association for consulting with an unqualified practitioner-a waming which has not required to be repeated. The recent defence of such conduct in Ireland shows how greatly the influence of such an Associa. tion is needed in that country.

I must not omit to remind you of the public condemnation of the Royal College of Physicians of Edinburgh. To their lasting disgrace, they had proclaimed what they called a year of grace-that is to say, they replenished their coffers by the sale of licences without even the pretence of any investigation, but easily satisfied with the signatures of two medical friends of the candidate for the diploma.

Homaopalhy. - Perhaps in no single instance has the Association done so much good as in defining the duty of its members towards the practitioners of homœopathy. At the annual meeting held in Brighton in 1851, it passed resolutions condemnatory of the practice of meeting homoopaths in consultation. In 1857, Dr. Horner, a Vice-President of the Association, was unanimously removed from his position on account of his having adopted homoeopathy. The Association did not cease reaffirming its opinions, till it became an accepted axiom that under no circumstances could medical men hold professional intercourse with practitioners of homcopathy. The importance of this de cision will be estimated at its true value when it is recollected that up to this time some of the leaders of the profession, whilst deriding the practice of homœeopathy, had not ceased publicly to proclaim their willingness to consult with homceopaths, setting at defiance the well known rule of medical ethics, that when the opinion of two consultants are irreconcilable, it is the duty of one of them to retire. But from this time (186I) no such conduct has been permitted.

I began by stating that, when the Association was founded, medicine was partly a trade, partly an art. I firmly believe that the trading portion is a thing of the past ; that it is now partly an art, but day by day more nearly approaches a science. The apothecary of the past is displaced by the highly educated practitioner of the present. The energy of ignorance, which in times past was frequently so dangerous, is but seldom to be met with. The poor can obtain the highest skill. But in no respect is the advance so great as in the altered tone of professional feeling. To be held up to the reprobation of the profession has become one of the greatest of punishments.

Brief allusion has been made to some of the successes achieved by the Association; others even greater must follow. The one portal system is but a question of time. The proper representation of the profession depends on the energy with which the struggle against vested en.

Do not suppose that in claiming so much for the Association I desire to undervalue the important aid which has been received from the different medical journals ; but, as the Association is the only recognised expression of professional feeling, without doubt it deserves the greatest share of the praise, in spite of the opinion expressed in certain quarters, " that its conduct is little else than a disgrace to the professional body of this country ; annual meetings, feasting, toasting, guzzling, complimenting, and puffing forming the chief features of that stupidly managed Society, the British Medical Association."

[An interesting pendant to the friendly and complimentary observations here quoted by Mr. May concerning associations such as our own, are contained in some observations of Professor Virchow quoted in a letter which we have received from our able correspondent in Berlin.]

\section{ABSTRACT OF A CLINICAL LECTURE ON THE MODE OF INVESTIGATING THE DISEASES OF WOMEN.}

BY ROBERT BARNES, M.D.,

Obstetric Physician, and Lecturer on Midwifery and Discases of Women and Children, at St. Thomas's Hospital.

GENTLEMEN, - I have now a few general observations to make to you on the mode of investigating the diseases of women. In a former lecture, I told you that we were guided by the subjective sensations of a woman in our first investigntions. When a woman complains of aching and pain in a part, we are naturally led to conclude that there is some mischief going on in the seat of pain, although there is no absolute certainty until we examine the organs suffering. In single women, we are chiefly guided by some disturbance of the function of menstruation. In many cases of disturbed menstruation, there exists some morbid condition which it is necessary to investigate. If there be intense pain and leucorrhceal discharge, we get the indication of disease requiring exploration. Discharges especially are significant, and render examination imperative. No woman suffers long from distressed menstruation or a discharge without danger of mischief. By examination, then, you come to a large class of objective signs, which, taken in conjunction with the suljictie'c signs, throw great light upon the disease. From the two together, you may come to a rational view of the case.

First, then, as to the ovary. The ovary is recognised now as the primum mobile, the first cause of menstruation. When menstruation is disturbed we should look to the ovary; although the uterus, being the organ of the discharge, should be looked to also. Still, if there be no ovary, there is no menstruation; if the ovary be diseased, there is likely to be difficult menstruation.

There are diseases, however, having their primary seat in the uterus. The uterus has a certain definite position, size, shape, mobility, or range of motion, sensibility and attachment. All these conditions can be examined by the touch, and any deviations from them must have a cause. There are some other properties of the uterus which we can bring under observation-such as its vascularity, colour, and alterations of surface. The speculum enables us to see the lower part of the uterus and the vagina, and is here of the greatest possible service; but nothing, of course, can enable us to see the ovary.

[Dr. Barnes then referred to a diagram of the uterus and its appendages in the healthy state, and proceeded to show how its position was affected by abnormal conditions.] If there be a large quantity of urine in the bladder, the uterus is thrown backward; if the rectum be loaded, the uterus is pressed forward. Sometimes the uterus is from this latter cause so pressed against the bladder that there is retention of urine. I have known distressing cases of this kind. There are no means of keeping the bladder free until you have washed out the rectum. As to change of size, if the uterus be much enlarged, and the other signs of pregnancy agree, we conclude that the woman is pregnant; but the minor sizes of the uterus are not so easily settled as the result of preg nancy. They may be the result of engorgement, or of mischief coming on after pregnancy, or of tumours, etc. If at the end of three weeks from confinement we find that the uterus is large, we conclude that in volution of the uterus has been arrested. The best way to ascertain the bulk of the uterus is to grasp it between the two hands. The sound will also measure the size of the uterus. The change of form chiefly indicates the presence of tumours in the uterus, which, springing out of its walls, alter its shape; or it may indicate a displacement. We ascertain the sensibility of this organ by the touch. Tenderness on pressure may arise from inflammation, or neuralgia, or irritability. There is supposed to be a simply hyperzesthetic condition of the organ, the slightest touch 